\title{
Is limiting transfusion safe? The devil is in the details
}

\author{
Victor A. Ferraris, MD, PhD, and Jeremiah P. Martin, MBBCh, FRCSI \\ From the Department of Surgery, University of Kentucky, Lexington, Ky. \\ Disclosures: Authors have nothing to disclose with regard to commercial support. \\ Received for publication Aug 31, 2015; accepted for publication Aug 31, 2015; available ahead of print Oct 1, \\ 2015. \\ Address for reprints: Victor A. Ferraris, MD, PhD, Department of Surgery, University of Kentucky, A301 Ken- \\ tucky Clinic, 740 S Limestone, Lexington, KY 40506-0284 (E-mail: ferraris@uky.edu). \\ J Thorac Cardiovasc Surg 2015;150:1032-4 \\ $0022-5223 / \$ 36.00$ \\ Copyright (C) 2015 by The American Association for Thoracic Surgery \\ http://dx.doi.org/10.1016/j.jtcvs.2015.08.109
}

There is an enormous body of evidence suggesting that a restrictive transfusion policy is at least as good, and possibly better than, a liberal transfusion strategy. On the other hand, every surgeon has seen transfusion save lives. Surgeons struggle with this dichotomy on an almost daily basis. Surgeons realize that some of the highest-risk patients cannot survive without transfusion. Perhaps 1 picture summarizes this relationship best: Figure 1 depicts the transfusionrelated odds of operative mortality and developing serious morbidity in selected patients included in the American College of Surgeons National Surgical Quality Improvement Program database. The Figure suggests that patients at least risk for operative mortality or serious operative morbidity had the greatest odds of experiencing an adverse surgical outcome if transfusions were given. The lowest-risk patients had an 8- to 10-fold increased risk of operative mortality or serious morbidity if they received transfusion compared with the highest-risk patients who had an almost insignificant mortality or morbidity risk associated with transfusion.

\section{RESTRICTING BLOOD TRANSFUSION}

The increased risk of transfusion in low-risk patients shown in Figure 1 does not automatically translate into an operational imperative. The definition of high risk or low risk is vague, and the data used to define transfusionrelated adverse outcomes are compromised by imprecise transfusion indications, failure to compare patients with equivalent transfusion risks, failure to accurately define subgroups of patients with apparent low mortality risk but increased transfusion risk, and incomplete understanding of the true risks of blood transfusion. However, when looking at blood transfusion it is important to realize that trauma and cardiac surgery account for nearly $30 \%$ to $40 \%$ of all blood products transfused in the United States. ${ }^{2}$ Logic suggests that many cardiac surgical patients fall into the highrisk group. No good guidelines can tell surgeons which low-risk patients benefit from transfusion. This uncertainty translated into a fairly robust attempt at limiting transfusion over the past 2 decades. At least 6 randomized controlled trials (RCTs) and many more observational studies have

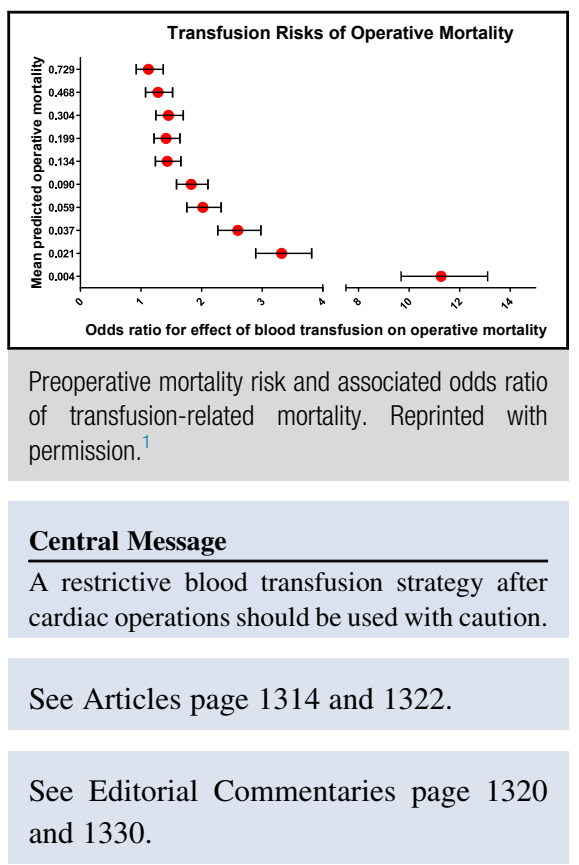

addressed the value of restricting blood transfusion and tolerating subsequent low hemoglobin levels in patients undergoing a variety of cardiac surgical procedures. There are many problems with design and interpretation of these studies and it is very difficult to make clinical decisions about tolerating low hemoglobin levels in surgical patients based on available published data.

An imprecise summary of available literature on limiting blood transfusion in cardiac operations suggests that a restrictive transfusion policy is probably as good as a liberal strategy, but there are some important caveats. The bulk of the literature that supports superiority of a restrictive transfusion policy is based on observational studies like the article by Ad and colleagues. ${ }^{3}$ RCTs have not been as universally supportive of a restrictive transfusion policy, similar to observational studies. ${ }^{4}$ Importantly, no RCTs have shown that transfusion in patients undergoing cardiac surgery should be withheld until hemoglobin thresholds reach 6 to $7 \mathrm{~g} / \mathrm{dL}$. For these reasons and others, published blood conservation guidelines are purposefully vague on the issue of restrictive versus liberal transfusion practices. 5,6

\section{WHAT TO EXPECT FROM A RESTRICTIVE TRANSFUSION STRATEGY}

The article by Ad and colleagues ${ }^{3}$ attempts to shed some light on this issue by presenting results from the Inova Cardiac Program. The authors' institution decided 
several years ago to adopt what most surgeons would consider a restrictive transfusion policy and this article is a summary of what surgeons can expect if their institutions do the same. They focus on a subgroup of supposed low-risk patients who have worse outcomes with a restrictive strategy (ie, older patients). More than anything, the authors point out that certain subgroups with low risk of mortality have greater risks from a restrictive transfusion policy. It would be very naïve to assume that age is the only discriminator that identifies low-risk patients who are at increased risk from a transfusion. One can predict that other patient factors like preoperative anemia, small body size, renal dysfunction, and preoperative antiplatelet medication are likely candidates for selecting low-risk patients likely to have adverse outcomes from blood transfusion. More careful and comprehensive RCTs are needed to address subgroups at increased risk from transfusion despite being lower risk for operative mortality.

\section{IS A RESTRICTIVE TRANSFUSION POLICY SAFE FOR EVERYONE?}

The key question remains. Is a restrictive transfusion policy safe and effective in limiting adverse events in all patients

\section{Transfusion Risks of Operative Mortality}

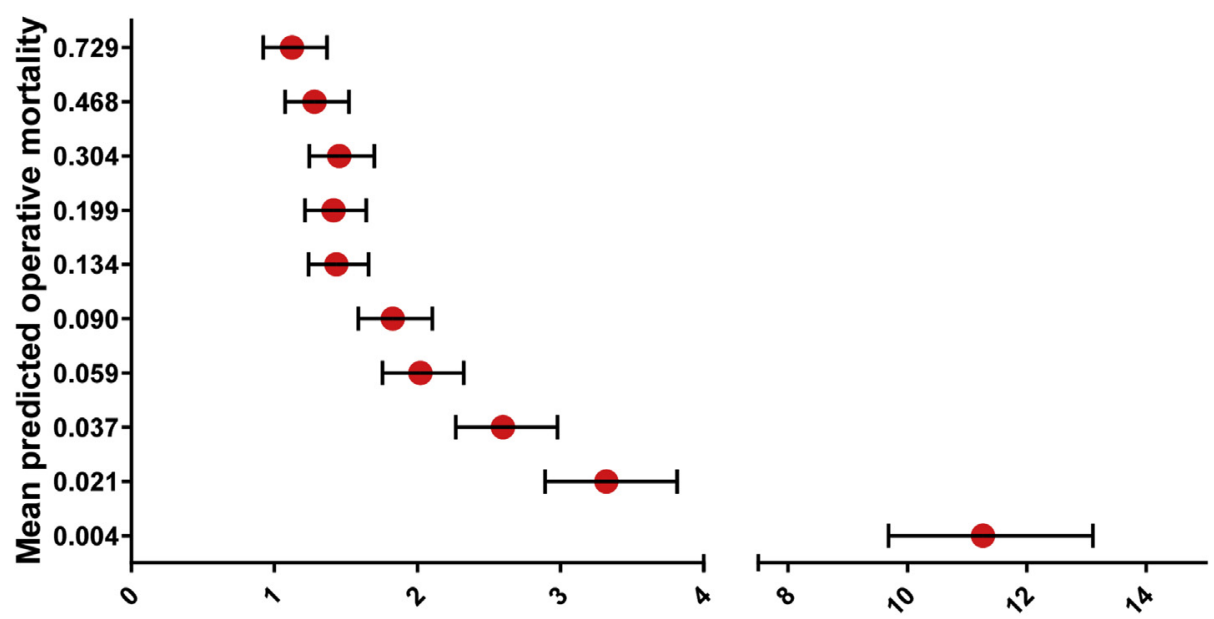

A Odds ratio for effect of blood transfusion on operative mortality

Transfusion and Risk of Serious Complications

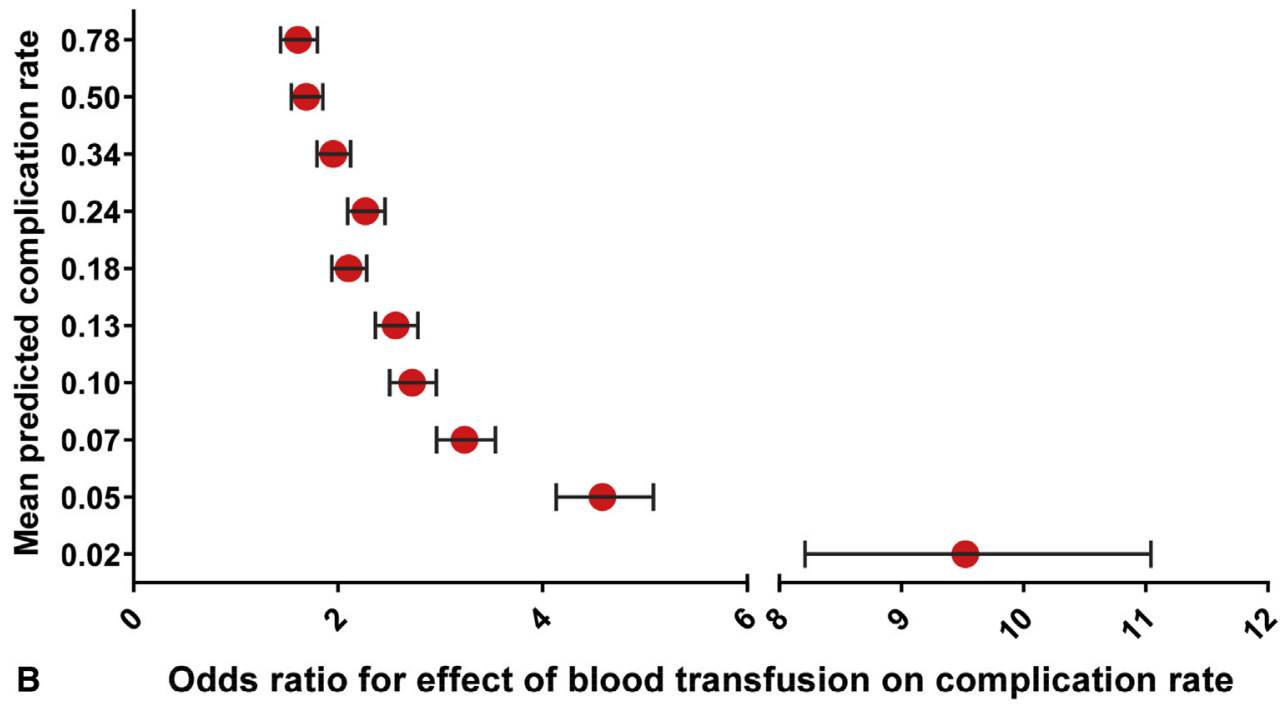

FIGURE 1. Odds ratios for adverse outcomes related to blood transfusion in selected patients included in the American College of Surgeons National Surgical Quality Improvement Program. A, Serious complications. B, Operative mortality. Reprinted with permission. ${ }^{1}$ 
undergoing cardiac surgery? Based on probably incomplete available evidence, a nonrigorous pseudoscientific answer to this question is that a restrictive transfusion strategy is at least as good as, and possibly better than, a liberal transfusion policy in patients undergoing low- to moderate-risk cardiac operations. This question would benefit from more focused RCTs and perhaps a systematic review with meta-analyses. Until more information is available, the answer is that surgeon experience usually wins out. Surgeons understand at a very visceral level that transfusion helps some patients. There are clearly outliers who believe that all cardiac surgical patients should have a hemoglobin level above 9 or $10 \mathrm{~g} / \mathrm{dL}$ and those surgeons who refuse transfusion regardless of clinical condition until a patient's hemoglobin level drops below $7 \mathrm{~g} / \mathrm{dL}$. The best option is probably somewhere between these extremes, but available evidence does not permit a more finetuned approach. There is a significant need for better identification of low- to moderate-risk patients who might benefit from a liberal transfusion strategy. A corollary to this premise is that it is likely that available evidence should not be used to make decisions for all patients undergoing cardiac operations. The implication that all patients should be subject to a restrictive transfusion strategy is painting with broad strokes. Like everything we do as surgeons, the devil is in the details.

\section{References}

1. Ferraris VA, Hochstetler M, Martin JT, Mahan A, Saha SP. Blood transfusion and adverse surgical outcomes: The good and the bad. Surgery. 2015;158:608-17.

2. Whitaker BI, Hinkns S. The 2011 National Blood Collection and Utilization Survey report. http://www.hhs.gov/ash/bloodsafety/2011-nbcus.pdf. Accessed September 10, 2015.

3. Ad N, Massimiano PS, Burton NA, Halpin L, Pritchard G, Shuman DJ, et al. Effect of patient age on blood transfusion after cardiac surgery. $J$ Thorac Cardiovasc Surg. 2015;150:209-14.

4. Murphy GJ, Pike K, Rogers CA, Wordsworth S, Stokes EA, Angelini GD, et al. Liberal or restrictive transfusion after cardiac surgery. $N$ Engl J Med. 2015;372: 997-1008.

5. Society of Thoracic Surgeons Blood Conservation Guideline Task F, Ferraris VA, Brown JR, Despotis GJ, Hammon JW, Reece TB, Saha SP, et al. 2011 update to the Society of Thoracic Surgeons and the Society of Cardiovascular Anesthesiologists blood conservation clinical practice guidelines. Ann Thorac Surg. 2011;91: 944-82.

6. Napolitano LM, Kurek S, Luchette FA, Corwin HL, Barie PS, Tisherman SA, et al. Clinical practice guideline: red blood cell transfusion in adult trauma and critical care. Crit Care Med. 2009;37:3124-57. 